\title{
ECOLOGICAL ASSESSMENT OF SELENIUM IN THE AQUATIC ENVIRONMENT
}

\author{
Peter M. Chapman ${ }^{1}$ \\ William J. Adams ${ }^{2}$ \\ Marjorie L. Brooks ${ }^{3}$ \\ Charles G. Delos ${ }^{4}$ \\ Samuel N. Luoma ${ }^{5}$ \\ William A. Maher ${ }^{6}$ \\ Harry M. Ohlendorf ${ }^{7}$ \\ Theresa S. Presser ${ }^{8}$ \\ D. Patrick Shaw ${ }^{9}$ \\ ${ }^{1}$ Golder Associates, Burnaby, BC, Canada \\ ${ }^{2}$ Rio Tinto, Magna, UT, USA \\ ${ }^{3}$ Southern Illinois University, Carbondale, IL, USA \\ ${ }^{4}$ USEPA, Washington, DC, USA \\ ${ }^{5}$ USGS, Menlo Park, CA, USA \\ ${ }^{6}$ University of Canberra, Canberra, ACT, Australia \\ ${ }^{7}$ CH2M HILL, Sacramento, CA, USA \\ ${ }^{8}$ USGS, Menlo Park, CA, USA \\ ${ }^{9}$ Environment Canada, Vancouver, BC, Canada
}

\begin{abstract}
To date there has been no clear guidance for assessing the potential environmental effects and impacts of selenium (Se) contamination; such activities have been highly site-specific. A Society of Environmental Toxicology and Chemistry (SETAC) Pellston Workshop held February 22-28, 2009, which involved a multidisciplinary and international group of scientists, managers and policymakers, established the present state of the science and provided globally-applicable guidance for assessing and managing the environmental effects of Se. Key information from the SETAC Pellston includes: traditional methods for predicting toxicity on the basis of exposure to dissolved concentrations do not work for Se; enrichment functions can be used to predict Se bioaccumulation at the base of food webs; uptake by individual species and in steps of the food web can be described by a trophic transfer function; Se partitioning is unique among metal and metalloid contaminants and requires site-specific risk assessments to a much greater extent than most other contaminants.
\end{abstract}

Key Words: selenium, aquatic, risk assessment, reproduction

\section{INTRODUCTION}

Selenium (Se) is a naturally occurring substance, and an essential element required for the health of humans, other animals, and some plants. It can be beneficial but it can also be toxic. When present in excess and in critical chemical species in the tissues of egg-laying vertebrates (fish, birds, amphibians, reptiles), it can cause reproductive failure or abnormalities.

Selenium concentrations are increasing in many areas of North America, Australia, New Zealand, and China, largely as a result of anthropogenic activities, and are likely increasing in other parts of the world. 
Historic Se contamination of Belews Lake, Hyco and Kesterton Reservoirs (US) resulted in wholeecosystem exposures, which had adverse population-level impacts. Few such impacts on populations have been documented in other ecosystems, particularly lotic systems, despite elevated Se concentrations. However, there are a number of water bodies in which Se concentrations are becoming elevated and in which such impacts could occur.

This paper briefly summarizes the key findings of the Pellston Workshop on "Ecological Assessment of Selenium in the Aquatic Environment." The workshop was sponsored by the Society of Environmental Toxicology and Chemistry (SETAC) and held February 22-28, 2009 in Pensacola (FL, USA). This SETAC Pellston Workshop brought 46 key individuals (4 continents, 5 countries) from business, academia, government, and nongovernmental organizations together with students to develop consensus on a path forward for the assessment of Se in the aquatic environment.

An Executive Summary Booklet is available at http://www.setac.org/node/265 (Chapman et al. 2009). The full technical proceedings of the workshop will be published separately by SETAC in 2010.

\section{KEY FINDINGS}

Key findings were as follows, relative to Se risk assessments in aquatic ecosystems:

\section{Problem Formulation:}

- Selenium is a growing problem of global concern.

- Diet is the primary pathway of Se exposure for both invertebrates and vertebrates.

- Traditional methods for predicting toxicity on the basis of exposure to dissolved concentrations do not work for Se because the behaviour and toxicity of Se in aquatic systems are highly dependent upon site-specific factors, including food web structure and hydrology (Figure 1).

- Selenium toxicity is primarily manifested as reproductive impairment due to maternal transfer, resulting in embryotoxicity and teratogenicity in egg-laying vertebrates.

\section{Environmental Partitioning, Bioaccumulation, and Trophic Transfer:}

- Understanding Se speciation is critical to understanding its mobility, transformation, partitioning in the environment, and potential risk to aquatic ecosystems (Figure 2).

- Selenium uptake is facilitated across most biological membranes (a nonpassive, carrier-mediated process), making its partitioning unique among metalloid contaminants.

- The single largest step in the bioaccumulation of Se occurs at the base of food webs, characterized by an "enrichment function" (Figures 1 and 3); thermodynamic or equilibriumbased principles are not appropriate for predicting Se bioaccumulation at the base of food webs.

- Selenium bioaccumulation by primary producers and predators varies widely among species, based on both ecology and physiology (biodynamics); uptake by individual species and in steps of the food web can be described by a trophic transfer function (Figure 1). 


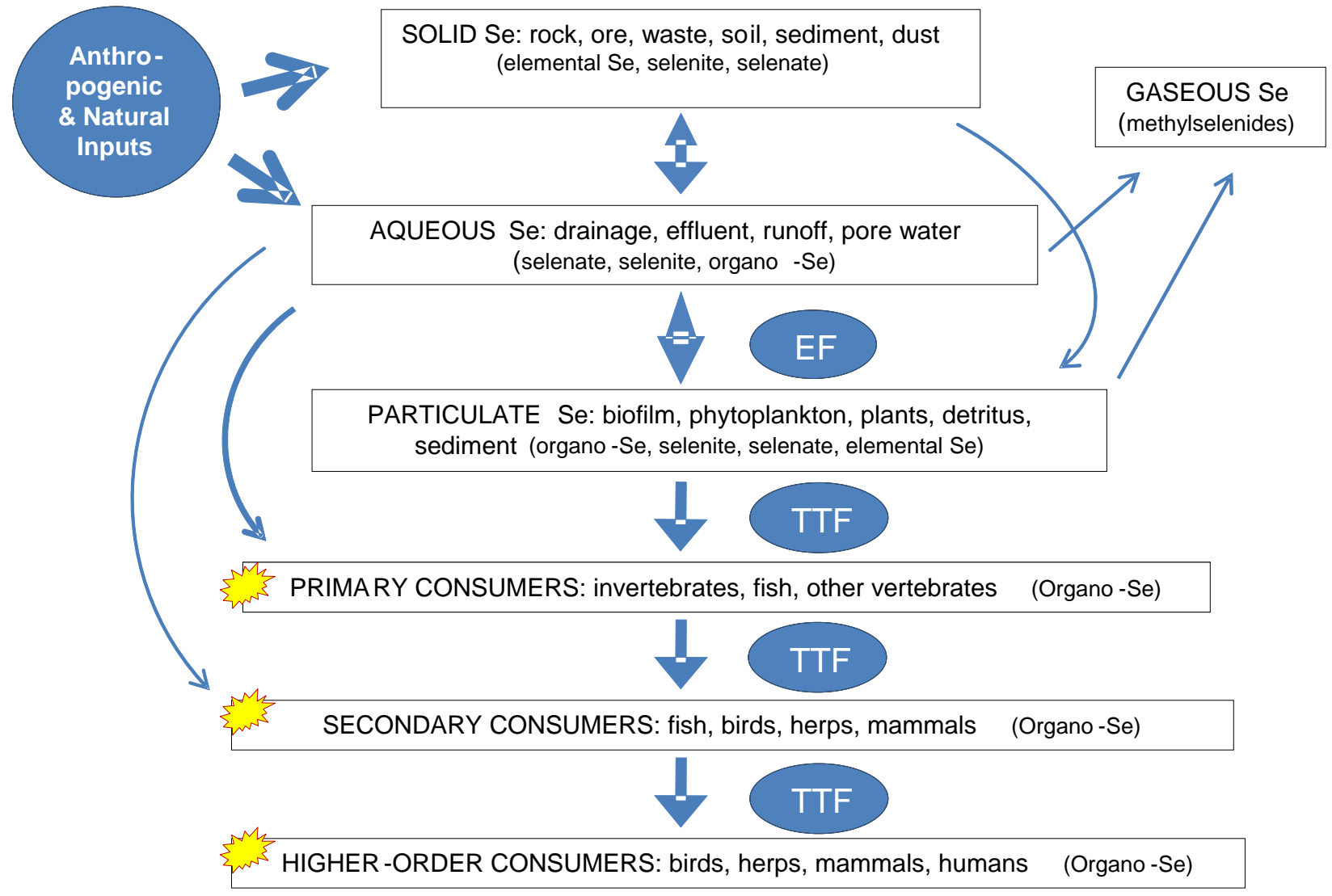

= SELENIUM HAZARD

Figure 1: Conceptual model depicting selenium dynamics and transfer in aquatic ecosystems. $\mathrm{EF}=$ enrichment factor; TTF $=$ trophic transfer function.

\section{$\underline{\text { Toxic Effects: }}$}

- A key aspect of Se toxicity is the narrow range between dietary essentiality and toxicity.

- Differences in species sensitivities to Se may be related to differences in reproductive physiology, dynamics of Se transfer from diet or body tissues to eggs, and/or differences in capacity to metabolize organic Se to more reactive oxidized species.

- Protection of top predators may not guarantee protection of all biota situated lower in the food web.

- Aquatic-dependent mammals do not appear to be as sensitive as fish or birds to dietary organic Se exposure.

- The most sensitive toxicity endpoint in birds is embryo mortality.

- The most sensitive toxicity endpoints in fish larvae are teratogenic deformities such as skeletal, craniofacial, and fin deformities, and various forms of edema.

- Embryo mortality and severe development abnormalities can result in impaired recruitment of individuals into populations. 


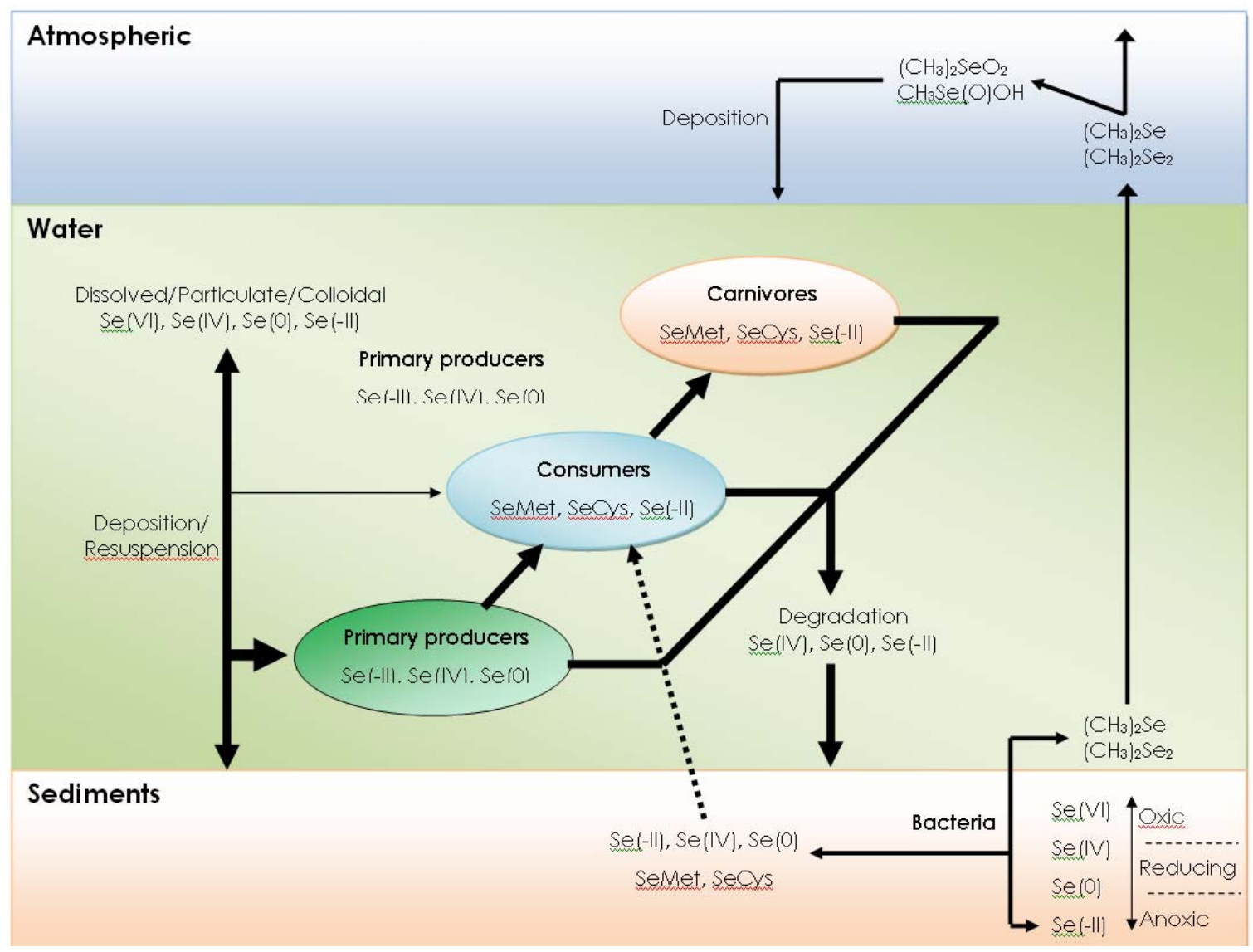

Figure 2: Selenium species associated with major processes in aquatic systems

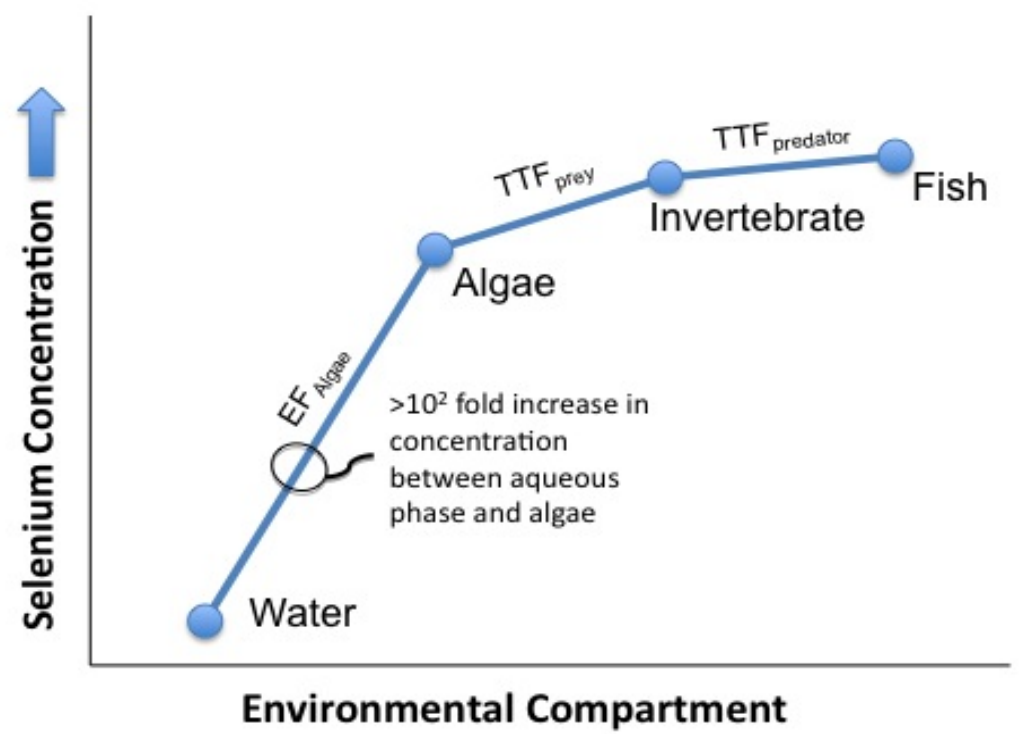

Figure 3: Selenium enrichment and trophic transfer in aquatic food webs. 


\section{Risk Assessment:}

- Population-level effects from Se in natural ecosystems are difficult to detect.

- This difficulty reflects differences in species sensitivity as well as food web complexities and demographics where population-level effects are suspected. Se contamination of Belews Lake and of Hyco and Kesterson Reservoirs (USA) resulted in whole-ecosystem exposures that had significant adverse population-level impacts. Few such widespread impacts on populations have been definitively documented in other ecosystems; however, population-level effects have been suspected at several other sites, including San Francisco Bay (USA) and Lake Macquarie (Australia).

- Risk assessment starts with reviewing available data on Se concentrations in various media, but more certainty in assessment of potential adverse effects is realized when Se measurements are made in reproductive tissue.

- A single, universal, dissolved water quality value is inappropriate for predicting toxicity. The dissolved Se concentration benchmark that is necessary to protect one site may be either insufficiently protective or unnecessarily protective at another site.

- There is consensus that fish and bird eggs are the critical media in terms of assessing or predicting Se toxicity at a given location, and measured concentrations in these tissues are most strongly linked to adverse effects.

- The vulnerability of a species is the product of its sensitivity to Se in its eggs, its propensity to transfer Se from its body into its eggs, and its propensity to accumulate Se from its environment, as affected by its diet choices and intake rates, and by site-specific factors controlling the transfer of Se into and within the food web.

- For reliable prediction of effect thresholds across a range of sites, numeric benchmarks for egg concentrations provide the greatest certainty. The more distantly connected a possible measurement medium is to the egg concentrations, the less certainty that the associated numeric benchmark will be appropriate across sites (Figure 4).

- For site-specific assessment of Se risks to fish, the field collection of ripe females or newly laid embryos for laboratory examination of larval effects is a reliable indicator of Se risks when the effect measure is related to the egg Se concentration.

- Selenium requires site-specific risk assessments, including adequate quality assurance and quality control of chemical and biological analyses, to a much greater extent than many other contaminants. 
Food Web Transfer of Se

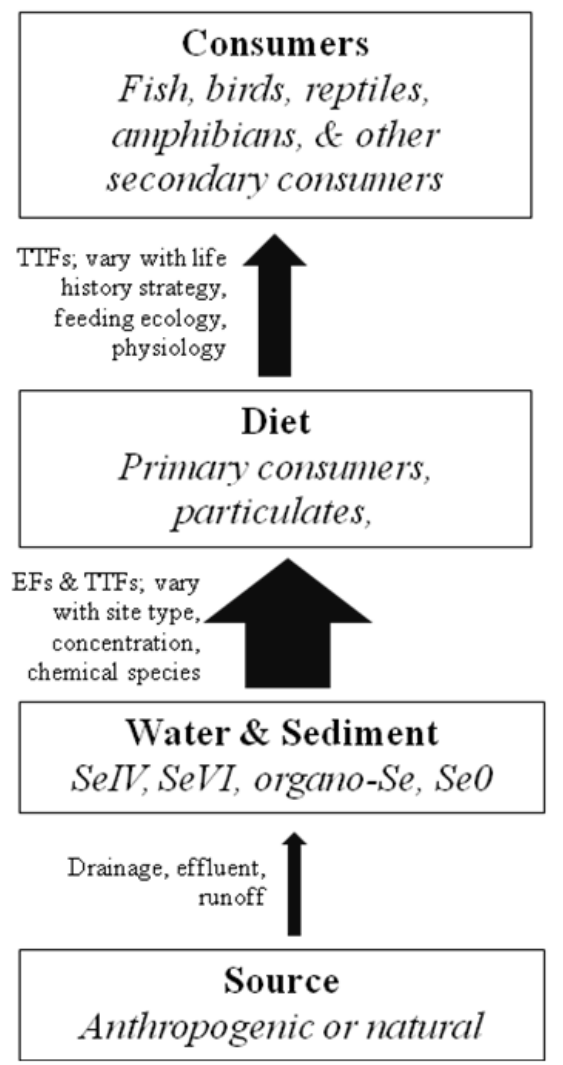

Confidence in Risk Assessment

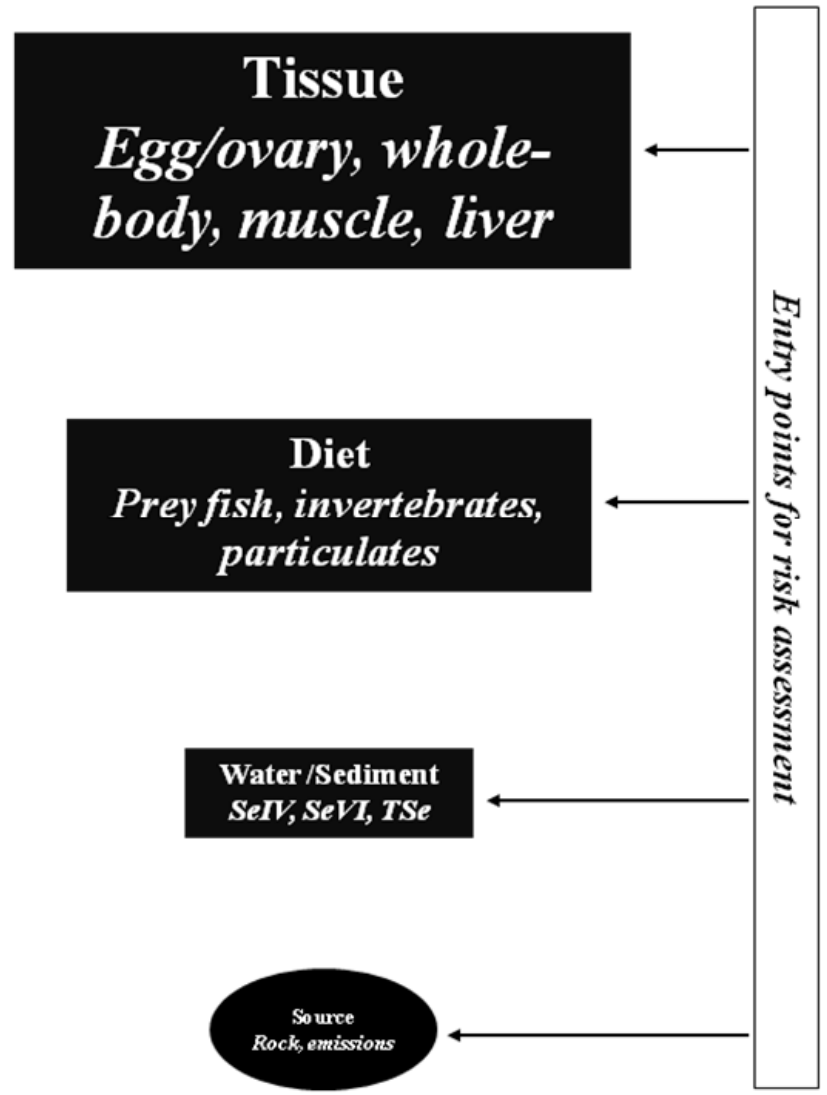

Figure 4: Conceptual pathway of Se transfer in aquatic ecosystems (left) and relative certainty with which Se concentrations in environmental compartments can be assessed in making accurate characterizations of risk. (The size of the arrows in the left column indicates the relative rates of transfer and the size of the compartment in the right column indicates the relative confidence for deriving estimated risks.)

\section{ACKNOWLEDGMENTS}

Financial support for the workshop is gratefully acknowledged from (in alphabetical order) the following: American Petroleum Institute; Australian Academy of Technological Sciences and Engineering (partially supported by the International Science Linkages-Science Academies Programme, part of the Australian Government Innovation Statement, Backing Australia’s Ability); Canadian Industry Selenium Working Group (comprising contributions from members, in alphabetical order: Areva, Cameco, CVRD Inco, Grand Cache Coal, Kemess, Peace River Coal, Prairie Mines, Shell, Sherritt Coal, Teck Coal, Teck Cominco, TransAlta, and Western Coal Corporation); Canadian Nuclear Safety Commission; CH2M HILL; Electric Power Research Institute; Environment Canada; Rio Tinto; US Environmental Protection Agency, Office of Water; US Fish and Wildlife Service; and US Utility Water Act Group. 


\section{REFERENCE CITED}

Chapman, P.M., W. J. Adams, M. L. Brooks, C. G. Delos, S. N. Luoma, W. A. Maher, H. M. Ohlendorf, T. S. Presser, D. P. Shaw. 2009. Ecological assessment of selenium in the aquatic environment. SETAC Press, Pensacola, FL, USA. 